\title{
A META-ANALYSIS COMPARING THE EFFICACY AND SAFETY OF TERLIPRESSIN AND OCTREOTIDE IN THE MANAGEMENT OF ACUTE VARICEAL BLEEDING
}

\author{
AKANKSHA MATHUR ${ }^{1 *}$, ACHAL SHARMA ${ }^{2}$ \\ ${ }^{1}$ Department of Pharmacology, Baroda Medical College, Vadodara, Gujarat, India. ${ }^{2}$ Department of Medicine, Holy Family Hospital, Delhi, \\ India. Email: akanksha.mathur1@gmail.com
}

Received: 29 August 2019, Revised and Accepted: 14 October 2019

\section{ABSTRACT}

Objective: Various clinical trials have compared terlipressin and octreotide in the management of acute variceal bleed, but their results have been inconsistent. Therefore, the present meta-analysis was performed to compare the clinical efficacy and safety of terlipressin and octreotide and gather the strength of evidence regarding their use in variceal hemorrhage.

Methods: Randomized control trials were identified using PubMed search engine and Cochrane clinical trial register (from 1994 to 2019). Initial hemostasis rate, rebleeding rate on the $5^{\text {th }}$ day, and overall mortality rate during the study period were studied. The extracted data were analyzed using review manager 5.3 software. Odds ratio with 95\% confidence intervals (CI) was estimated for the dichotomous outcomes.

Results: A total of six randomized control trials were identified. Through comparisons of data for terlipressin and octreotide groups, we found no statistically significant differences in the initial hemostasis rate, rebleeding rate on the $5^{\text {th }}$ day, and overall mortality rate between the different treatment approaches.

Conclusion: The comparison of terlipressin and octreotide showed them to be equally effective and safe therapeutic agents in patients of acute variceal bleeding. Further, evidence from the future randomized controlled trials with higher quality and larger sample sizes is needed to confirm these findings.

Keywords: Variceal bleeding, Esophageal varices, Vasoconstrictors, Terlipressin, Octreotide.

(C) 2019 The Authors. Published by Innovare Academic Sciences Pvt Ltd. This is an open access article under the CC BY license (http://creativecommons. org/licenses/by/4. 0/) DOI: http://dx.doi.org/10.22159/ajpcr.2019.v12i12.35509

\section{INTRODUCTION}

Acute variceal bleeding is an emergency condition where the patient may deteriorate suddenly and may succumb to death, if not appropriately managed. In spite of all the advances in medical science and technology, it still accounts for up to $20 \%$ mortality at 6 weeks [1]. The outcome of an episode of an active hemorrhage depends on the control of active bleeding and prevention of associated complications. The first step, in the management, is the initiation of pharmacologic therapy along with simultaneous hemodynamic resuscitation [2].

Pharmacological therapy typically consists of vasopressors. They contract the gastrointestinal blood vessels, thereby decreasing the blood flow to the portal vein. This reduces the portal venous pressure resulting in hemostasis. In addition to that, these agents also provide a clearer view of an endoscopic procedure, if needed.

Octreotide, a somatostatin analog, and terlipressin, a derivative of vasopressin, are commonly used as vasopressors. While octreotide causes only splanchnic vasoconstriction, terlipressin has dual effects both splanchnic and systemic vasoconstriction that may predispose to systemic adverse effects. It has been found that terlipressin decreases mortality rates in patients with acute variceal bleeding while there is a limited subset of data regarding efficacy of octreotide. These two classes of pharmacotherapy have been evaluated in several studies; but controversy exists regarding their overall risks and benefits [3,4]. Few meta-analyses have been conducted, but they have compared the vasoactive agents with interventions such as endoscopic procedure or band ligation. According to recent guidelines, these two modalities are used concurrently and this comparison does not reflect standard of care [5]. Few studies focused solely on the comparison of efficacy of the two drugs while others, only on complications arising after hemostasis was achieved [3]. Therefore, the study has been designed with the aim to compare both the efficacy and safety of terlipressin and octreotide in the management of acute variceal bleed. In this regard, it would be first of analysis to compare and contrast two commonly used pharmacological approaches with regard to the risks involved as well as benefits observed.

\section{METHODS}

\section{Data source}

Studies were identified using an electronic database such as MEDLINE, PubMed search engine, and Cochrane clinical trial register.

Randomized controlled trials (RCTs) comparing terlipressin and octreotide in patients with acute upper gastrointestinal variceal bleeding were included in the study. The use of endoscopy, either for diagnostic or therapeutic purposes, was permitted as long as both the groups were treated equally. The database was searched for the studies with inclusion criteria from 1994 to 2019. Our search was limited to RCTs only.

The primary outcome of interest was to determine the efficacy of the agent to control active bleeding. The secondary outcomes included rebleeding on the $5^{\text {th }}$ day and overall mortality during the study period. Complications occurring due to therapy were also analyzed.

\section{Statistical analysis}

Two investigators independently assessed each study to determine eligibility. The discrepancy was sought using Cohen's kappa statistic. Quality of clinical trials was assessed on the basis of method of the randomization, allocation concealment, and blinding [5]. 
Review Manager Software Version 5.3 was used to conduct metaanalysis using a fixed-effect model [6]. For dichotomous data, odds ratio (OR) with $95 \%$ CI was used. $\mathrm{I}^{2}$ statistic was used to determine statistical heterogeneity. The $\mathrm{I}^{2}$ value of $<25 \%, 25-50 \%$, and $>50 \%$ were considered as low, moderate, and high heterogeneity, respectively.

\section{RESULTS}

We screened 59 citations, and six were selected for full-text retrieval. All six studies met our inclusion criteria (Fig. 1).

All six studies had adequate randomization involving methods such as computer-generated random numbers or use of random number tables. Of six studies, three had adequate allocation concealment; two were double blind and one single blind.

A total of 1129 study participants in six trials comparing terlipressin with octreotide were included in the study. The mean age of participants was $49.7 \pm 6.8$ years. The study characteristics of the studies are shown in Table 1.

Figure 2 shows the forest plot comparison of the initial hemostasis rate of the two groups, terlipressin, and octreotide in acute variceal bleed. The fixed-effects model showed a trend toward terlipressin with OR of 0.96 (95\% CI: 0.66-1.42; p=0.86). However, this result was statistically not significant. There was moderate heterogeneity noted among the studies evidenced by $\mathrm{I}^{2}$ of $36 \%$.
The risk of rebleeding during the hospital stay was not found to be statistically significant $\left(\mathrm{OR}=0.75,95 \% \mathrm{CI}\right.$ : 0.51-1.10; $\left.\mathrm{p}=0.14 ; \mathrm{I}^{2}=52 \%\right)$, as shown in Fig. 3. One of the trials reported zero incidences of rebleeding in both the comparator groups.

There was no statistical evidence of a difference in all-cause mortality at 42 days (OR=0.98, 95\% CI: 0.66-1.47; p=0.93) (Fig. 4). Remarkably, no heterogeneity was noted among the studies, as evidenced by $\mathrm{I}^{2}=0$.

There were no serious adverse events reported in any of the trials. The most common adverse event reported in both the treatment groups in all the studies was hyponatremia. Other adverse reactions reported were mild and mostly related to gastrointestinal system. Two of six trials with 581 participants contributed to the data on safety of terlipressin and octreotide in the management of variceal bleeding. There was no statistically significant difference in the complications due to therapy with octreotide than with terlipressin (OR=2.05, 95\% CI: 0.80-5.76; $\mathrm{p}=0.10$; $\mathrm{I}^{2}=64 \%$ ).

\section{DISCUSSION}

There was no statistically significant difference observed in the initial hemostasis achieved by either terlipressin or octreotide. This finding is also supported by other studies $[3,10]$. However, according to one study, terlipressin was found to be significantly less effective in controlling bleeding within $24 \mathrm{~h}$ as compared to octreotide [11]. However, the analysis included only two studies with relatively smaller sample size. Moreover, they were conducted $>20$ years ago.

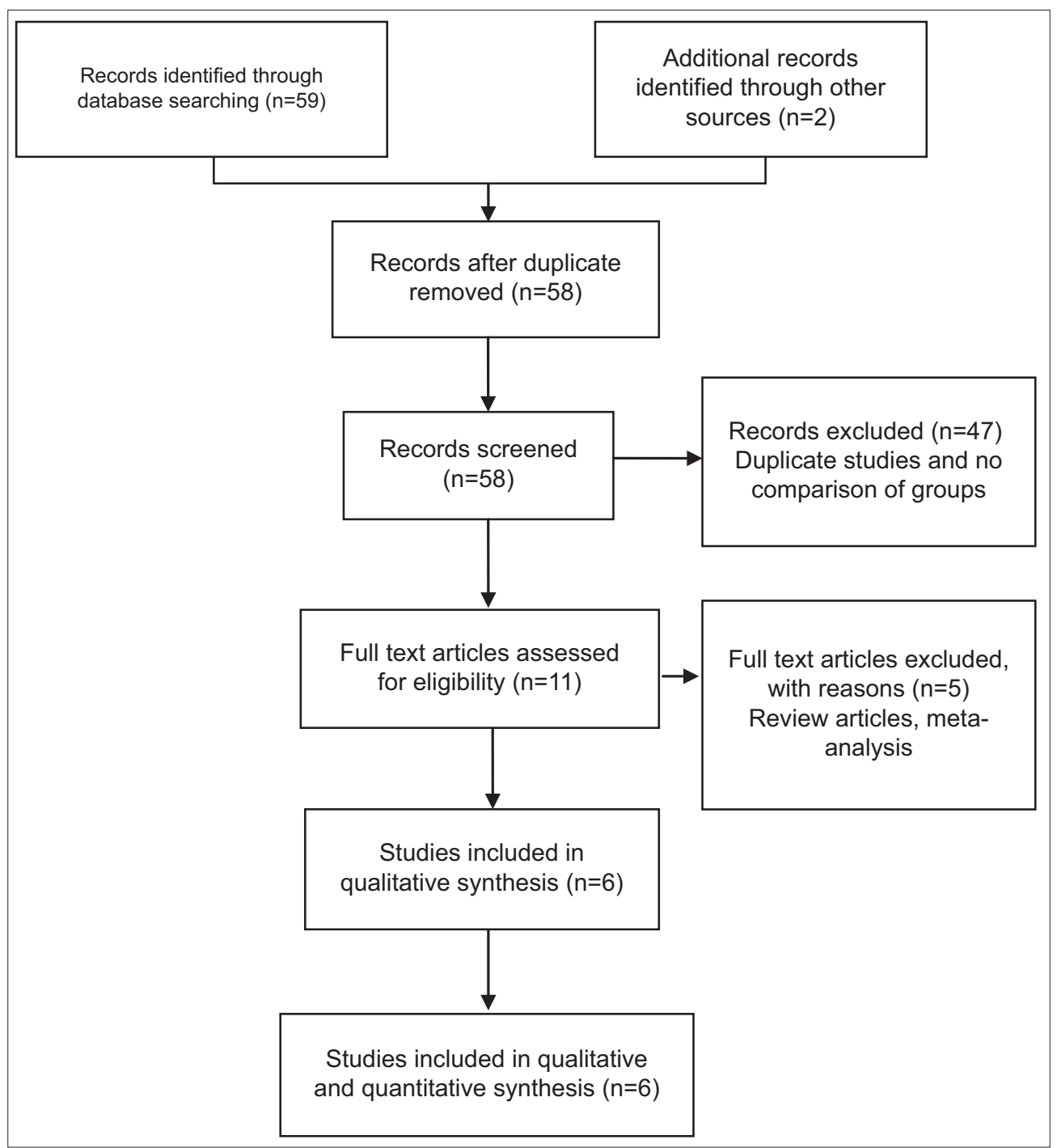

Fig. 1: Inclusion of studies for data analysis 
Table 1: Study characteristics

\begin{tabular}{|c|c|c|c|c|c|c|}
\hline \multirow[t]{2}{*}{ S. No. } & \multirow[t]{2}{*}{ Study } & \multirow[t]{2}{*}{$\mathbf{N}$} & \multicolumn{2}{|l|}{ Dose } & \multicolumn{2}{|c|}{ Duration of treatment (days) } \\
\hline & & & Terlipressin & Octreotide & Terlipressin & Octreotide \\
\hline 1. & $\begin{array}{l}\text { Abid et al.,[7] } \\
2009\end{array}$ & 324 & $\begin{array}{l}2 \times 10^{-3} \mathrm{~g} \text { by IV bolus followed by } \\
1 \times 10^{-3} \mathrm{~g} \text { IV every } 6 \mathrm{~h}\end{array}$ & $\begin{array}{l}100 \mu \mathrm{g} \text { IV bolus followed by a } \\
\text { continuous infusion at } 50 \mu \mathrm{g} / \mathrm{h}\end{array}$ & 3 & 3 \\
\hline 2. & $\begin{array}{l}\text { Asad and } \\
\text { Alam,[2] } 2014\end{array}$ & 80 & $\mathrm{NM}$ & NM & NM & NM \\
\hline 3. & $\begin{array}{l}\text { Brunati et al.,[8] } \\
1996\end{array}$ & 56 & NM & NM & NM & NM \\
\hline 4. & $\begin{array}{l}\text { Cho et al.,[9] } \\
2016\end{array}$ & 88 & $\begin{array}{l}2 \times 10^{-3} \mathrm{~g} \text { IV followed by } 1 \times 10^{-3} \mathrm{~g} \\
\text { every } 4 \mathrm{~h}\end{array}$ & Continuous infusion $25 \mu \mathrm{g} / \mathrm{h}$ & 3 & 5 \\
\hline 5. & $\begin{array}{l}\text { Pedretti } \\
\text { et al.,[10] } 1994\end{array}$ & 60 & $\begin{array}{l}\text { Day } 1: 2 \times 10^{-3} \text { g intravenous bolus } \\
\text { every } 4 \mathrm{~h} \text {, Day } 2: 2 \times 10^{-3} \text { g every } \\
6 \text { h, Day } 3-7: 1 \times 10^{-3} \text { g every } 6 \mathrm{~h}\end{array}$ & $\begin{array}{l}\text { Day } 1: 100 \mu \mathrm{g} \text { bolus followed } \\
\text { by continuous IV infusion at } \\
25 \mu \mathrm{g} / \mathrm{h} \text {; Day } 2: 100 \mu \mathrm{g} \text { t.i.d. SC }\end{array}$ & 7 & 7 \\
\hline 6. & Seo et al.,[4] 2014 & 521 & $\begin{array}{l}2 \times 10^{-3} \mathrm{~g} \text { by IV bolus followed by } \\
1 \times 10^{-3} \mathrm{~g} \text { IV every } 6 \mathrm{~h}\end{array}$ & $\begin{array}{l}50 \mu \mathrm{g} \text { IV bolus followed by a } \\
\text { continuous infusion at } 25 \mu \mathrm{g} / \mathrm{h}\end{array}$ & 5 & 5 \\
\hline
\end{tabular}

N: Sample size; NM: Not mentioned

\begin{tabular}{|c|c|c|c|c|c|c|c|c|c|c|}
\hline \multirow[b]{2}{*}{ Study or Subgroup } & \multicolumn{2}{|c|}{ Terlipressin } & \multicolumn{2}{|c|}{ Octreotide } & \multirow[b]{2}{*}{ Weight } & \multirow{3}{*}{$\begin{array}{c}\text { Odds Ratio } \\
\text { M-H, Fixed, } 95 \% \mathrm{Cl}\end{array}$} & \multirow{2}{*}{\multicolumn{4}{|c|}{$\begin{array}{c}\text { Odds Ratio } \\
\text { M-H, Fixed, } 95 \% \mathrm{Cl}\end{array}$}} \\
\hline & Events & Total & Events & Total & & & & & & \\
\hline Abid $S$ et al & 151 & 163 & 154 & 161 & $21.8 \%$ & & & $=-$ & $\Gamma$ & \\
\hline Asad M et al & 39 & 40 & 35 & 40 & $1.7 \%$ & $5.57[0.62,50.03]$ & & & & \\
\hline Brunatti et al & 22 & 28 & 21 & 28 & $8.6 \%$ & $1.22[0.35,4.24]$ & & & & \\
\hline Cho SB et al & 42 & 43 & 43 & 45 & $1.9 \%$ & $1.95[0.17,22.36]$ & & & & \\
\hline Pedretti $G$ et al & 16 & 30 & 23 & 30 & $20.6 \%$ & $0.35[0.11,1.05]$ & & & & \\
\hline Seo et al & 234 & 261 & 229 & 260 & $45.4 \%$ & $1.17[0.68,2.03]$ & & & & \\
\hline Total $(95 \% \mathrm{Cl})$ & & 565 & & 564 & $100.0 \%$ & $0.96[0.66,1.42]$ & & & & \\
\hline Total events & 504 & & 505 & & & & & & & \\
\hline $\begin{array}{l}\text { Heterogeneity: } \mathrm{Chi}^{2}= \\
\text { Test for overall effect }\end{array}$ & $\begin{array}{l}7.80, d f= \\
Z=0.18\end{array}$ & $\begin{array}{l}5(P=0 \\
=0.86\end{array}$ & 6) & & & & 0.01 & $\begin{array}{c}0.1 \\
\text { Favours [terlipressin] }\end{array}$ & Favours [octreotide] & $100^{\circ}$ \\
\hline
\end{tabular}

Fig. 2: Initial hemostasis rate

\begin{tabular}{|c|c|c|c|c|c|c|c|c|c|c|}
\hline \multirow[b]{2}{*}{ Study or Subgroup } & \multicolumn{2}{|c|}{ Terlipressin } & \multicolumn{2}{|c|}{ Octreotide } & \multirow[b]{2}{*}{ Weight } & \multirow{2}{*}{$\begin{array}{l}\text { Odds Ratio } \\
\text { M-H, Fixed, } 95 \% \mathrm{Cl}\end{array}$} & \multirow{2}{*}{\multicolumn{4}{|c|}{$\begin{array}{c}\text { Odds Ratio } \\
\text { M-H, Fixed, } 95 \% \mathrm{Cl}\end{array}$}} \\
\hline & Events & Total & Events & Total & & & & & & \\
\hline Abid S et al, 2009 & 25 & 151 & 38 & 154 & $52.2 \%$ & $0.61[0.34,1.06]$ & & & & \\
\hline Asad M et al, 2014 & 12 & 43 & 4 & 40 & $5.0 \%$ & $3.48[1.02,11.91]$ & & & & \\
\hline Brunatti et al, 1996 & 6 & 28 & $?$ & 28 & $9.1 \%$ & $0.82[0.24,2.84]$ & & & & \\
\hline Cho SB et al, 2016 & 5 & 43 & 12 & 43 & $17.6 \%$ & $0.34[0.11,1.07]$ & & & & \\
\hline Pedretti $G$ et al, 1994 & 0 & 30 & 0 & 30 & & Not estimable & & & & \\
\hline Seo et al, 2014 & 8 & 261 & 10 & 260 & $16.1 \%$ & $0.79[0.31,2.04]$ & & & & \\
\hline Total $(95 \% \mathrm{Cl})$ & & 556 & & 555 & $100.0 \%$ & $0.75[0.51,1.10]$ & & & & \\
\hline Total events & 56 & & 31 & & & & & & & \\
\hline $\begin{array}{l}\text { Heterogeneity: } \mathrm{Chi}^{2}= \\
\text { Test for averall effect: }\end{array}$ & $\begin{array}{r}41, d f=4 \\
=1.46(P\end{array}$ & $\begin{array}{l}(P=0.0 \\
=0.14)\end{array}$ & (8); $F^{2}=5$ & & & & 0.01 & $\begin{array}{c}0.1 \\
\text { Favours [terlipressin] }\end{array}$ & $\frac{10}{1} \frac{1}{\text { Favours [octreotide] }}$ & 100 \\
\hline
\end{tabular}

Fig. 3: Rebleeding

\begin{tabular}{|c|c|c|c|c|c|c|c|c|c|c|c|}
\hline \multirow[b]{2}{*}{ Study or Subgroup } & \multicolumn{2}{|c|}{ Terlipressin } & \multicolumn{2}{|c|}{ Octreotide } & \multirow[b]{2}{*}{ Weight } & \multirow{2}{*}{$\begin{array}{c}\text { Odds Ratio } \\
\text { M-H, Fixed, } 95 \% \mathrm{Cl}\end{array}$} & \multirow{2}{*}{\multicolumn{5}{|c|}{$\begin{array}{c}\text { Odds Ratio } \\
\text { M-H, Fixed, } 95 \% \mathrm{Cl}\end{array}$}} \\
\hline & Events & Total & Events & Total & & & & & & & \\
\hline Abid S et al, 2009 & 9 & 163 & 7 & 161 & $13.9 \%$ & $1.29[0.47,3.54]$ & & & & & \\
\hline Asad M et al, 2014 & 4 & 40 & 5 & 40 & $9.4 \%$ & $0.78[0.19,3.14]$ & & & & & \\
\hline Brunatti et al, 1996 & 4 & 28 & 4 & 28 & $7.2 \%$ & $1.00[0.22,4.47]$ & & & & & \\
\hline Cho SB et al, 2016 & 7 & 43 & 8 & 45 & $13.7 \%$ & $0.90[0.30,2.74]$ & & & & & \\
\hline Pedretti $G$ et al, 1994 & 9 & 30 & 8 & 30 & $11.7 \%$ & $1.18[0.38,3.63]$ & & & & & \\
\hline Seo et al, 2014 & 21 & 261 & 23 & 260 & $44.2 \%$ & $0.90[0.49,1.67]$ & & & & & \\
\hline Total $(95 \% \mathrm{Cl})$ & & 565 & & 564 & $100.0 \%$ & $0.98[0.66,1.47]$ & & & & & \\
\hline Total events & 54 & & 55 & & & & & & & & \\
\hline $\begin{array}{l}\text { Heterogeneity: } \mathrm{Chi}^{2}= \\
\text { Test for overall effect: }\end{array}$ & $\begin{array}{l}58, d f=5 \\
=0.09(P\end{array}$ & $\begin{array}{l}(P=0.9 \\
=0.93)\end{array}$ & $99) ; 1^{2}=09$ & & & & 0.01 & 0.1 & & 10 & $\overrightarrow{100}$ \\
\hline
\end{tabular}

Fig. 4: Mortality

Recurrent hemorrhage rates did not differ significantly between the two drug therapies. The same observation was found in other studies as well $[3,10]$. The risk of rebleeding is very high within $24 \mathrm{~h}$ extending up to the first 10 days. It parallels the survival rate and hence directly influences the outcome of acute variceal bleeding.

Furthermore, no statistically significant difference between overall mortality rates was found in the study $[3,10]$. Survival rates have been improved in the past few years due to better quality of care, newer modalities of the diagnosis and treatment, and, last but not least, the development of early warning scores. However, it is still associated with 15-20\% mortality.

The study revealed no statistically significant difference between the complications arising due to either therapy. However, data regarding safety of the drugs were available in two of the six studies. Theoretically, terlipressin is presumed to have lesser ischemic events as compared to vasopressin, but the risk is still present. At high doses, hyponatremia may occur [12]. On the other hand, octreotide is associated with 
milder gastrointestinal adverse effects. Serious adverse effects are not commonly encountered.

It was found that the use of terlipressin was associated with shorter hospital stay as compared to octreotide. However, this was a finding from a single study and hence cannot be generalized. Further studies are required to clarify this issue [4].

In practice, the choice of pharmacological agents is usually based on availability and cost. Terlipressin is not available in the United States; therefore, octreotide is commonly prescribed as vasopressor to arrest bleeding. Affordability to the patient is another important issue to be addressed on, especially in developing countries like India. While the common regimen of terlipressin is an initial dose of $2 \times 10^{-3} \mathrm{~g}$ IV every $4 \mathrm{~h}$ and then titrated down to $1 \times 10^{-3} \mathrm{~g}$ IV every $4 \mathrm{~h}$ once hemorrhage is controlled, octreotide is being prescribed as bolus $50 \times 10^{-6} \mathrm{~g} \mathrm{IV}$ followed by a continuous IV infusion. Discrepancies in the initial doses and the duration of therapy have been noted in regimens of various guidelines as also evident in this study. The optimal duration of pharmacological therapy has not been well established. In RCTs, the duration of vasoactive treatment was found to be variable ranging from 3 days to 7 days.

The study has certain limitations. Poor to moderate quality of supporting evidence as well as smaller sample size of trials could have influenced the results. Few studies did not clearly state if blinding, allocation concealment and intention-to-treat analysis was performed. A wide range of publication dates (1996-2019) was selected to strengthen the analysis. However, standard clinical practices may vary from one time period to another contributing to heterogeneity. Nevertheless, heterogeneity was found to be low to moderate in our study. In the case of overall mortality, it was found to be zero.

\section{CONCLUSION}

Terlipressin was found to be non-inferior to octreotide regarding its efficacy in controlling the variceal bleed. Moreover, the complications and mortality rates did not differ significantly between the two groups. Therefore, either of the two drugs can be used in the management of acute variceal bleeding. However, firm conclusions cannot be drawn due to mentioned limitations. Large RCTs with adequate quality are warranted for further research.

\section{AUTHORS' CONTRIBUTIONS}

All authors contributed equally to the paper.

\section{CONFLICTS OF INTEREST}

The authors declare that there are no conflicts of interest regarding the publication of this article.

\section{REFERENCES}

1. Sarin SK, Kumar A, Angus PW, Baijal SS, Baik SK, Bayraktar Y, et al. Diagnosis and management of acute variceal bleeding: Asian pacific association for study of the liver recommendations. Hepatol Int 2011;5:607-24.

2. Asad M, Alam MF. A comparison of terlipressin and octreotide for the control of esophageal variceal bleeding in patients of liver cirrhosis. Clin Exp Hepatol 2014;4:86-8

3. Wells M, Chande N, Adams P, Beaton M, Levstik M, Boyce E, et al. Meta-analysis: Vasoactive medications for the management of acute variceal bleeds. Aliment Pharmacol Ther 2012;35:1267-78.

4. Seo YS, Park SY, Kim MY, Kim JH, Park JY, Yim HJ, et al. Lack of difference among terlipressin, somatostatin, and octreotide in the control of acute gastroesophageal variceal hemorrhage. Hepatology 2014;60:954-63.

5. Jüni $P$, Altman DG, Egger M. Systematic reviews in health care: Assessing the quality of controlled clinical trials. BMJ 2001;323:42-6.

6. Review Manager (RevMan) [Computer Program]. Ver. 5.3. Copenhagen: The Nordic Cochrane Centre, The Cochrane Collaboration; 2014.

7. Abid S, Jafri W, Hamid S, Salih M, Azam Z, Mumtaz K, et al. Terlipressin vs. Octreotide in bleeding esophageal varices as an adjuvant therapy with endoscopic band ligation: A randomized double-blind placebo-controlled trial. Am J Gastroenterol 2009;104:617-23

8. Brunati XC, Curioni R, Brunelli L, Repaci G, Morini L. Sclerotherapy alone vs scherotherapy plus terlipressin vs sclerotherapy plus octreotide in the treatment of acute variceal hemorrhage. Hepatology 1996;24:207-8.

9. Cho SB, Park KJ, Lee JS, Lee WS, Park CH, Joo YE, et al. Comparison of terlipressin and octreotide with variceal ligation for controlling acute esophageal variceal bleeding a randomized prospective study. Korean J Hepatol 2006;12:385-93

10. Pedretti G, Elia G, Calzetti C, Magnani G, Fiaccadori F. Octreotide versus terlypressin in acute variceal hemorrhage in liver cirrhosis. Emergency control and prevention of early rebleeding. Clin Investig 1994;72:653-9.

11. Zhou X, Tripathi D, Song T, Shao L, Han B, Zhu J, et al. Terlipressin for the treatment of acute variceal bleeding: A systematic review and meta-analysis of randomized controlled trials. Medicine (Baltimore) 2018;97:e13437.

12. Hegazy R, Moustafa R, El-meligy R. The therapeutic and neuroprotective effects of green tea in a rat model of terlipressininduced chronic hyponatremia. Int J Pharm Pharm Sci 2016;8:253-9. 